\title{
DIREITO ROMANO
}

(Para uso dos alumnos do $1 .^{\circ}$ anno do curso juridico)

PARTE I

Generalidades

CAPITULO I

Do Direito

§ $10^{\circ}$-Accepções do vocabulo $j u s-D i r e i t o$ objectivo e direito subjectivo

A palavra-jus-direito-que, segundo todas as probabilidades, parece vir do sanskrito-IU-, raiz,que significa uma idéa de ligação, de vinculo, como se nota nos vocabulos Jugum, Jungere, (I)-é empregada, nos textos romanos, com diversas accepções, como adverte Paulo no fr. I I de just et jure (I-I), quando diz:-jus pluribus modis dicitur.

Dessas varias accepções, as mais importantes são aquellas pelas quaes o direito é indicado ou como uma lei-norma agendi, ou como um poder-facultas agendi, exprimindo aquillo que os juristas costumam

(I) IHERING, L'Esprit $d u$ Dr. Rom.; I, pag. 219 (trad. de MeuleNAERE, I886, 3." ed.)-ED. CUQ., Inst. jur. des rom., I, pag. 54 (ed. I89I). 
denominar-direito no sentido objectivo, e direito no sentido subjectivo. No primeiro sentido, o direito se manifesta como a lei emanada do poder competente, como a regra com a qual devem os homens conformar todos os seus actos juridicos na vida social.

Desde que o homem exerce a sua actividade ao lado de outros individuos eguaes, que coexistem na mesma sociedade, necessita sujeitar o exercicio de suas faculdades aos limites traçados pelas condições necessarias á vida e ao desenvolvimento do individuo e da associação, condições que constituem a substancia das regras de conducta, as quaes passam depois a ser formuladas, pela autoridade competente, em verdadeiras leis juridicas destinadas a reger o povo. A estas leis adjectiva o poder publico o predicado da coacção material, para que os individuos sejam forçados a obedecel-as, não lhes sendo possivel qualquer transgressão.

E' neste sentido de lei, de instituições juridicas, que se vê a expressão jus-empregada, por excellencia, na linguagem romana, em sua generalidade. Essa é a significação dos precepta juris (2) de Ulpiano, que, abrangem, em sua comprehensão, todas as normas do direito positivo dos romanos, apresentando-o, exclusivamente, na sua feição objectiva, de norma, ou de preceito. O mesmo Ulpiano usa da expressão jus no fr. 9 de legibus ( $\mathrm{I}-3)$, restringindo o seu significado para indicar apenas o preceito legislativo emanado da autoridade romana:-non ambiguitur senatum jus facere posse, mostrando não ser duvidoso que o senado, no seu tempo, pudesse fazer lei. E' neste sentido ainda que se usa da expressão ipso jure, para traduzir aquilllo que decorre immediatamente da lei, sem necessidade da intervenção de um acto do homem (3).

(2) Fr. Io $\S$ I de just. et jur. (I-I).

(3) GLück, Alle Pandette, $\S \mathrm{I} .^{\circ}$ 
No sentido subjectivo, o direito é empregado como o poder da pessôa, a faculdade que tem o homem de obrar, exercendo a sua actividade sobre as cousas que o cercam, ou mesmo sobre actos dos seus semelhantes. Dotado desse poder, o homem é livre de praticar todos os actos, emquanto não perturbe o poder egual que compete a cada homem na sociedade. As liberdades de todos os associados devem harmonisar-se, de modo que a esphera de liberdade de cada um, isto é, o seu poder de agir, seja limitado pelas espheras eguaes de liberdade dos outros (4).

O homem, pois, se reconhece, na vida social, como um ente dotado desse poder de fazer o que queira, sob os limites acima referidos. $O$ poder publico protege-lhe a acção, assegurando-lhe a liberdade de agir, e demarcando, ao mesmo tempo, em fórmu. las precisas, as linhas que traçam os limites que não devem ser transpostos. Essa faculdade do homem, garantida, em sua manifestação, pelas normas juridicas, constitúe o direito no sentido subjectivo, o qual, como diz Savigny, mais claramente se patenteia, quando, sendo negado ou atacado por outrem, a autoridade judiciaria intervem para reconhecer-lhe a sua existencia e extensão (.5).

Ao direito, assim considerado, corresponde sempre um dever gerạl de respeito por parte de todos os outros individuos, que existem na sociedade, o que deu logar a dizer-se que jus et obligatio sunt correlata.

Releva notar, porém, que este brocardo só contém um cunho de verdade, desde que se tome a obligatio, não no sentido restricto do direito romano, mas no daquella obrigação geral, que todos têm de respeitar o direito de outrem.

(4) Spencer, Justice, cap. VI-Trat. CASTelot, I893, Kant.

(5) Savigny, Trait. de Dr. Rom., trad. Guenoux, 1855, pag. 7. 
O jus, nessa accepção de faculdade ou poder, encontra-se constantemente usado na linguagem romana, como se vê, por exemplo, nas expressões-jus pignoris, jus venandi, que indicam o poder juridico sobre o objecto do penhor, ou a faculdade que o homem tem de caçar,-e jus quiritium designando a reunião dos direitos privativos do cidadão romano.

Com o mesmo significado, parece usar Ulpiano da palavra jus, na sua definição de justiça, exprimindo com ella o direito que cada um tem na sociedade. (6)

A epigraphe do liv. I. ${ }^{\circ}$ tit. 8 das Institutas-de his qui sui vel alieni juris sunt--apresenta-nos o jus tambem considerado sob o ponto de vista de um poder. (7)

Porisso, no mesmo titulo se dividem os homens em sui juris e alieni juris, referindo-se a primeira classe áquelles que são de seu proprio direito, isto é, que não se acham sob o poder de ninguem, e a segunda, áquelles que são dependentes, isto é, que estão debaixo do poder de outrem - in potestate parentium ou in potestate dominorum.

Além dessas duas accepções principaes, de que temos tratado, encontra-se ainda o jus, nos textos, traduzindo significações differentes: ora indica a norma que, por traduzir uma obrigatoriedade relativa, é considerada como tendo força de lei, tal como a disposição testamentaria feita por um cidadão livre -utı legassit super pecunia tutelave suce rei, ita Jus esto-(8), ou a sentença pronunciada por um juiz competenteJus ex sententia judicis fieri (9); ora refere-se á praxe segundo a qual tem sido adoptada uma opinião-quo
(6) Fr. ro de just. et jur. (I-I) Inst. princ h. t. (I-I).
(7) D. L. I Tit. 6 .
(8) XII Tab.-V-III.
(9) Fr. I 7 I de inoff. test. (5-2). 
jure utimur (10); ora aponta a relação moral sobre que se fundam alguns direitos e obrigaçōes entre certas pessôas-nonnunquam Jus etiam pro necessitudine dicimus: veluti Est mihi JUS cognationis, vel adfnitatis (I I); ora mostra simplesmente as qualidades da cousa objecto do direito-JURA praidiorum: bonitas, salubritas, amplitudo (I 2); ora equivale ao titulo que dá logar á acquisição de um direito real-si quis diuturno usu, et longa quasi prossessione, Jus aqua ducenda nanctus sit, non est ei necesse docere de jure, quo aqua constituta est (I 3 ); ora designa o logar onde o magistrado exerce a sua jurisdicção-in jure,--contraposto áquelle onde o judex, examinando o facto, applicava o direito que lhe era indicado-in judicio (14); ora exprime a forma do processo, ou a organisação judiciaria, distinguindo-se o jus ordinarium e o jus extraordinarium conforme o processo obedecesse á ordem commum estabelecida, ou dispensasse algumas das formalidades existentes-qua non habent JURIS ordinarii executionem (I 5); ora diz respeito á forma de testar prescripta pela lei, como se vê nas phrasestestamentum JURE factum e non JURE factum (16); ora circumscreve a idéa apenas ao jus civile, distinguindo-o do direito pretoriano, como se vê nesta disposição:et parvi refert utrum jure sit constiütus usufructus, an vero tuitione pratoris (I7); : ora é empregada em um sentido mais elevado, para significar a sciencia do direito ou a jurisprudencia; é essa a idéa que se con-

(10) Fr. 27 § I de pactis (2-I4).

(I I) Fr. I 2 de just. et jur. (I-I).

(12) Fr. 86 de verb. signif. (50-I6).

(13) Fr. Io princ.-si serv. vind. (8-5)-Fr. 26 de aqua, et aquoe pluvice (39-3).

(I4) Fr. I $\$ 2$ de postulando (3-I)-Fr. 3 I ne quis eum (2-7)-D. L. 2 Tit. $4,-$ L. I I Tit. I.

(I5) Fr. 178 \& 2 de verb. signif. (50-16).

(I6) Fr. 24 de his quae ut indig. 34-9).

(17) Fr. I quibus mod. ususfr. (7-4) Fr. I § 5 quod fals, tut.: (27-6). 
tém na epigraphe do Digesto e das Institutas-de justitia et jure (I-I), e na definição de direito que se acha no fr. I princ. desse titulo. Dahi a denominação de juris consulti (I 8), juris prudentes (I9), juris peritı (20), para designar os que cultivam o estudo da sciencia juridica.

Dessa indicação, summariamente feita, das principaes accepções em que é usado o vocabulo jus, nos textos romanos, sem se acompanhar de qualificativo algum, vê-se a necessidade que tem sempre $o$ interprete de, no estudo das controversias apresentadas, firmar bem seguramente o verdadeiro sentido daquella palavra.

\section{$\S 2 .^{\circ}-$ Conceito do direito entre os romanos}

Muito elevada era a idéa que os jurisconsultos romanos formavam do direito; e, ao passo que o reconheciam como uma necessidade pratica, indispensavel á vida do individuo e á do Estado, contemplavam-no tambem pelo lado philosophico, dando-lhe a feição das virtudes moraes.

Abrindo-se o Digesto, no titulo--de justitia et jure-, os frags. dos jurisconsultos, que ahi se encontram, confirmam patentemente a verdade do enunciado. Logo no frag. I..$^{\circ}$ princ., as palavras de Ulpiano nos mostram o direito em uma significação das mais alevantadas, definindo-o, como o fizera CELso, ars boni et aqui. E tão distincta é a funcção de cultivar o direito, que, aos encarregados dessa tarefa, não vacilla em denominar sacerdotes, os quaes cultivam a justiça, e professam a sciencia do bom e do equita-

(18) Fr. Io pr. de grad. (38-10).

(I9) Fr. $2 .^{\circ} \S 5 .^{\circ}$ quis ordo in poss. $(38-15)$.

(20) Fr. de excusat. (27-1). 
tivo, distinguindo o justo do injusto, o licito do illicito, e procurando tornar os homens bóns, não só pelo temor das penas, mas tambem pela esperança das recompensas, segundo o determina uma verdadeira e não simulada philosophia (2 I).

Este alto concepto do direito, que é um consectario natural da influencia exercida pelos principios da escola estoica sobre o espirito dos jurisconsultos romanos, acha-se, do mesmo modo, manifesto, quando UlPiano nos dá a definição da justiça, da jurisprudencia, e estabelece quaes sejam os preceitos do direito.

A justiça não é simplesmente o-jus suum cuique tribuendi, mas é, necessariamente, uma-constans et perpetua voluntas (22). Mais do que uma affectio animi, segundo a definição de CicERo (23), o jurisconsulto romano entendia que ella era uma voluntas, no sentido da escola de ZENon; isto é, uma impulsão firme e consciente para o bem, opposta á libido ou á cupiditas. Era, portanto, uma virtude, como já o reconhecia o mesmo CiCERo, dizendo:- - Fustitia porro ea virtus est, qua sua cuique tribuits (24).

Tambem não basta á jurispridencia ser a justi atque injusti scientia, mas é necessario que seja a divinarum atque humanarum rerum notitia (25).

Os jurisconsultos, como os sabios, deviam ter um conhecimento de todas as cousas divinas e humanas, para poderem attingir a sciencia do justo e do injusto.

A jurisprudencia estava, pois, quasi elevada á classe da sabedoria, como a conceituavam os estoicos:

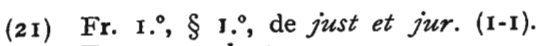

(22) Fr. 10 pr. h. t.

(23) CICERO-de finiz. $\mathrm{V}-23$.

(24) Id. de rep. III cap. XXXVII.

(25) Fr. $10 \S 20^{\circ} \mathrm{h} . \mathrm{t}$. 
"Quidam sapientiam ita finierunt, ut dicerent. eam divi norum et humanorum scientiam» (26).

$\mathrm{E}$ ao compendiar as regras juridicas, vasando-as todas no molde formado pelos tres preceitos fundamentaes, Ulpiano, dominado sempre pelo impulso nobre de uma alta philosophia, lançou, em primeiro logar, o lemma-honeste vivere, (27) como advertindo aos homens que o alterum non loedere, e o suum cuique tribuere so se podem exercitar na vida social, tendo elles os olhos fitos no fanal inextinguivel do honestum.

Se Ulpiano deixou-se arrebatar a tão grande altura para emittir a idéa que formava do direito, PAULo lhe não ficou em nada distanciado, quando escreveu que o direito natural é-quod semper aquum ac bonum est (28).

E Garo, que se ateve quanto possivel dentro nos limites da observação historica, poude, todavia, apontar como o fundamento daquelle direito de que todos os povos usam, a naturalis ratio (29), não se elevando, entretanto, á alta expressão das formulas philosophicas de Ulpiano e de Paulo.

\section{§ 3.-Distincção entre o direito e a moral}

Por definirem estes jurisconsultos o direito como o bonum et aquum e por haver Justiniano, acolhido taes definições, dando-lhes logar proeminente no. Digesto e nas Institutas, poder-se-á concluir que os romanos não distinguiam a moral do direito?

Embora os preceitos moraes e os juridicos se não manitestassem muito distinctos, nos primeiros tempos,

(26) SENECA-Epistola LXXXIX.

(27) Fr. Io cit.

(28) Fr. II h. t.

(29) Fr. 9 h. t., fr. 1 de adq. rer. dom. $(46-r)$. 
devido ao estado de homogeneidade e confusão, que dominam as regras de conducta, no alvorecer da vida de um povo (30), todavia, o destaque de umas e outras normas se vai produzindo lentamente, e os caracteristicos differenciaes se apresentam de modo a não poderem passar despercebidos aos jurisconsultos.

Os romanos, pois, dotados daquella maravilhosa faculdade para a comprehensão dos estudos juridicos; incorreriam na justa censura que se lhes irrogasse, se não déssem mostras de descortinar a differença entre o que é da esphera da moral, e o que pertence ao dominio do direito.

Os textos citados de Ulpiano e de Paulo, não rebatem a censura, e apenas nos autorizam a registrar confusão manifesta.

Porisso Accarias (3 I) declara que os jurisconsultos nem sempre: souberam resguardar-se da confusão entre o direito e a moral. Entretanto, a despeito dos citados textos, que indicam a maior despreoccupação no tocante ao differençar a moral do direito, o mesmo PAULo nos offerece a mais cabal advertencia, declarando francamente que nem tudo o que é licito é honesto-non omne, quod licet, honestum est (32), e, por consequencia, demonstrando que havia uma idéa clara entre aquillo pue é legal ou de direito, e o que pertence á moral. Convém observar, com os commentadores, que PaUlo, não quiz indicar, com o frag. citado, uma opposição existente entre as normas moraes e juridicas, mas a palavra-licet-por elle empregada, significa que o direito, embora não autorize, é, ás vezes, indifferente a que se cumpram certos preceitos, que a moral condemna.

(30) Cogliolo, Fil del Dir. Priv. pag. 25 (ed. Barbéra).

(3I) AcCarias, Precis de Dir. Rom.n. I.

(32) Fr. 144-de reg. jur. (50-17). 
A mesma differença entre o licito e o honesto encontra-se no texto de Modestrino (33)-semper in conjunctionibus, non solum quid liceat considerandum est, sed et quid honestum sit.

Póde dizer-se, pois, que os romanos não desconheciam a distincção entre a moral e o direito, embora não haja um texto preciso, que nos dê nitida idéa dessa differença.

Antes, o que se observa no corpo do direito, é um conjuncto de innumeros dispositivos em que, ao lado de certa confusão que as palavras permittem, se estabelece aquella harmonia intima e necessaria, que deve ligar a moral e o direito, e que é a resultante derivada do magno preceito:-honeste vivere.

E' porisso que diz Paprniano:-qua facta loedunt pietatem, existimationem, verecundiam nostram, et (ut generaliter dixerim) contra bonos mores funt: nec facere nos posse credendum est (34); е Pomponio indica, como preceito de direito das gentes, o amor a Deus, a obediencia aos progenitores eá patria, (fr. 2 de just et jur (I-I).

Convem ainda citar, em abono de Ulpiano, para se não poder inferir que elle permittia ao direito invadir a esphera da moral, o fr. I 8-de panis (48-I9) em que prescreve que ninguem póde ser punido pela simples intenção.-Cogitationis panam nemo patitur.

Dessas considerações desume-se que, se ha textos sobre os quaes póde assentar alguma duvida quanto á maneira de entender a moral e o direito, todavia, elementos existem que nos autorisam a concluir que os jurisconsultos romanos descortinavam a distincção entre os preceitos moraes e juridicos.

(Continia)

\section{Dr. Reynaldo Pochat.}

(33) Fr. 42-deritu (nupt. 23-2).

(34) Fr. 15-de cond. institut (28-7). 